\title{
Uso de geotecnologias na identificação da ocupação urbana em área de preservação permanente (APP) no município de Cunha - SP.
}

\author{
Thiago Lobão Cordeiro ${ }^{1}$ \\ Efraim Gregório Ferraz ${ }^{2}$ \\ René Novaes Júnior ${ }^{3}$ \\ Yhasmin Mendes de Moura ${ }^{4}$ \\ ${ }^{1}$ Centro Universitário Salesiano de São Paulo - UNISAL \\ Caixa Postal 515 - 12600-100 - Lorena - SP, Brasil \\ e-mail: cordeiro@dsr.inpe.br \\ ${ }^{2}$ Prefeitura Municipal da Estância Climática de Cunha - SP \\ Caixa Postal 515 - 12530-000 - Cunha - SP, Brasil \\ e-mail: efraimgf@hotmail.com \\ ${ }^{3}$ Instituto Nacional de Pesquisas Espaciais - INPE \\ Caixa Postal 515 - 12245-970 - São José dos Campos - SP, Brasil \\ e-mail: rene@dsr.inpe.br \\ ${ }^{4}$ Universidade de Taubaté \\ Caixa Postal 515 - 12201-970 - Taubaté - SP, Brasil \\ e-mail: yhasmin@dsr.inpe.br
}

\begin{abstract}
The objective of this work was to present urban occupation permanent protection areas located in Cunha, São Paulo state. For this, was used orbital satellite images from the Landsat TM 5 for 1987, 1997 and 2007. The images provide the identification of urban sprawl related to their years, will also be used on a topographic map scale of 1:10,000, micro basin of the Rodeio river hydrographic basin, which cuts across the urban area. This material will help with the preparation of distance map from the Rodeio river, which according to the Forestry Code will indicate areas of permanent protection. Through the crossing overlay is possible to quantify the areas of occupation. As this becomes easier and more feasible to know the results provided by the irregular occupation, and therefore develop policies to minimize these environmental impacts.
\end{abstract}

Palavras-chave: sensoriamento remoto, ocupação urbana, área de preservação permanente 


\section{Introdução}

Na caracterização proposta por Müller (1969) dos sítios urbanos do Alto Vale do Paraíba, Cunha é identificada como uma cidade assentada sobre terreno elevado, com declividade acentuada, embora ocupe o esporão mais amplo e de vertente mais suave do conjunto, isso faz com que a estrutura e a organização espaço urbano sejam influenciados pelas condições geomorfológicas do sítio urbano. A aglomeração urbana de Cunha surgiu e se impôs no decorrer da História, como um núcleo intermediário entre o Vale do Paraíba e o litoral sul do Estado do Rio de Janeiro, servindo durante muito tempo como pouso estratégico para as tropas vindas de Minas Gerais e que seguiam em direção ao porto de Paraty/RJ. A influência que a antiga Estrada Real (que acabou sendo utilizada também no transporte do café valeparaibano) exerceu sobre a formação do núcleo urbano foi tão marcante que o espaço urbano se projetou verticalmente de forma alongada, acompanhando a estrada que ligava litoral ao interior (MÜLLER, 1969), e até os dias de hoje, esse antigo traçado se constitui a espinha dorsal do arruamento da cidade.

Cunha apresenta até então, uma ocupação urbana desordenada, fruto da inexistência de um planejamento em sua formação, característica compartilhada pela maioria absoluta das cidades brasileiras, devido a diversos fatores histórico-sociais. Dentre eles, ao rápido processo de urbanização ocorrido no país, que conforme Santos (2005, p.31), se deu em apenas quatro décadas do século passado onde a taxa de urbanização saltou de 26,35\% em 1940 para $68,68 \%$ em 1980. Esse processo inseriu o país na lógica capitalista global, possibilitando a expansão do consumo, a formação de um mercado nacional, a terceirização da economia e esforços técnicos cada vez maiores visando a integração do território, por outro lado, com o crescimento repentino e desordenado das cidades, decorrente da migração da população rural, provocou inúmeros problemas como a ampliação da pobreza e do desemprego. (SANTOS, 2005).

Segundo o Art. 182 da Constituição Brasileira, o controle do uso e ocupação do solo é de responsabilidade do Poder Público municipal, que através de diretrizes fixadas em lei possa ordenar a ocupação adequada do território garantindo o desenvolvimento urbano e o bemestar dos habitantes. Consciente dos processos históricos e do papel da Administração Pública municipal perante a Constituição Federal, este trabalho tem como objetivo identificar a ocupação urbana em áreas de preservação permanente (APP) margem de rio, gerando com isso o mapeamento da área urbana e da micro-bacia do Córrego do Rodeio, bem como a quantificação da ocupação urbana nas APP's. Servindo de subsídios para políticas públicas futuras que visem à preservação e o equilíbrio entre sociedade e natureza. Tendo em vista a inexistência de uma lei municipal a respeito das APP's este trabalho terá como referência a Lei Federal $n^{\circ} 7.083 / 89$ do Art. $2^{\circ}$ do Código Florestal que define as áreas de preservação permanente nas margens de rios como sendo de trinta metros ao longo de rios ou qualquer curso d'água com menos de dez metros de largura.

\section{Materiais e Métodos}

O município da Estância Climática de Cunha está localizado no Vale do Paraíba paulista, entre as Coordenadas Geográficas, Latitude Sul e Longitude $44^{\circ} 41^{\prime}$ a $45^{\circ}$ 07' W. O município, formado pela junção de dois distritos (Cunha e Campos de Cunha), conta com um território de $1.047 \mathrm{~km}^{2}$, área que o torna o $11^{\circ}$ maior município em extensão territorial do Estado de São Paulo. Segundo o Censo realizado em 2007 pelo Instituto Brasileiro de Geografia e Estatística (IBGE), a população total é de 22.951 habitantes. A atividade econômica do município baseia-se principalmente na pecuária (leiteira e de corte) e na 
agricultura (milho, feijão, etc.), embora nos últimos anos o setor de serviços vem crescendo bastante, tendo em vista o desenvolvimento turístico do município.

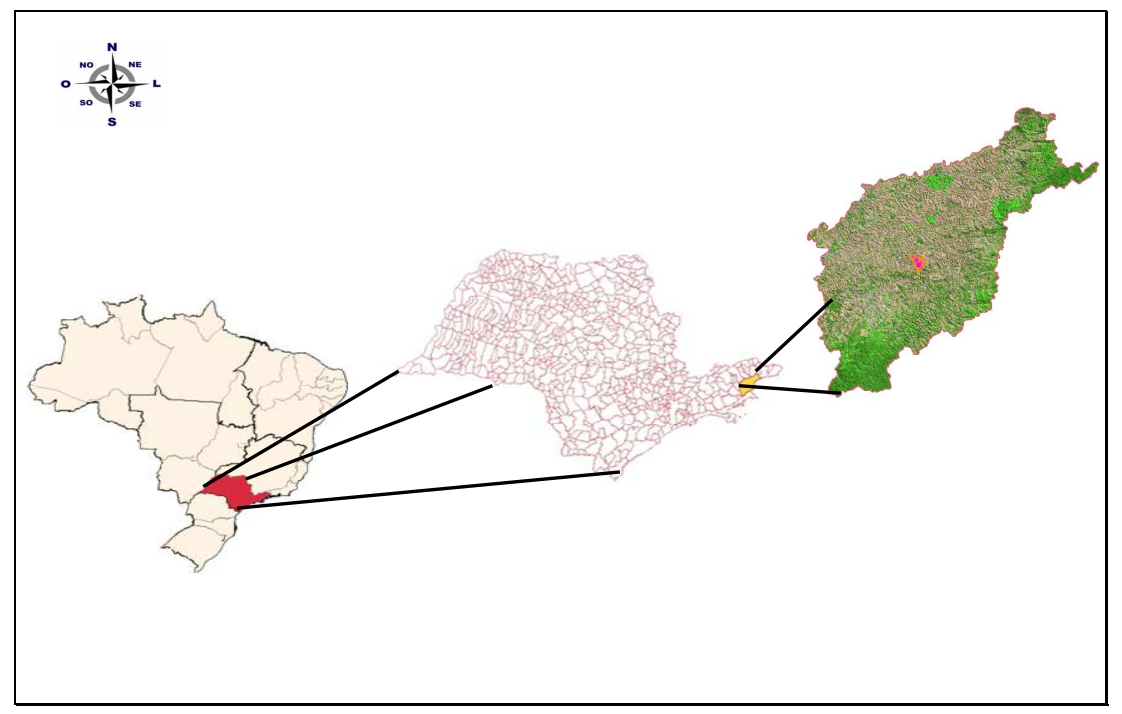

Figura 1 - Localização da área de estudo.

O presente trabalho foi desenvolvido utilizando-se de geotecnologias, que segundo Coppock (COPPOCK, 1995 apud MARCELINO, 2007, p.14), consiste no conjunto de tecnologias relacionadas à geoinformação, como o Sensoriamento Remoto, o Sistema de Posicionamento Global (GPS), o Sistema de Informações Geográficas (SIG) e a Cartografia Digital, possibilitando maior eficiência na geração, produção de dados e informações sobre os fenômenos geográficos em estudo.

O desenvolvimento do trabalho está baseado nas seguintes etapas metodológicas:

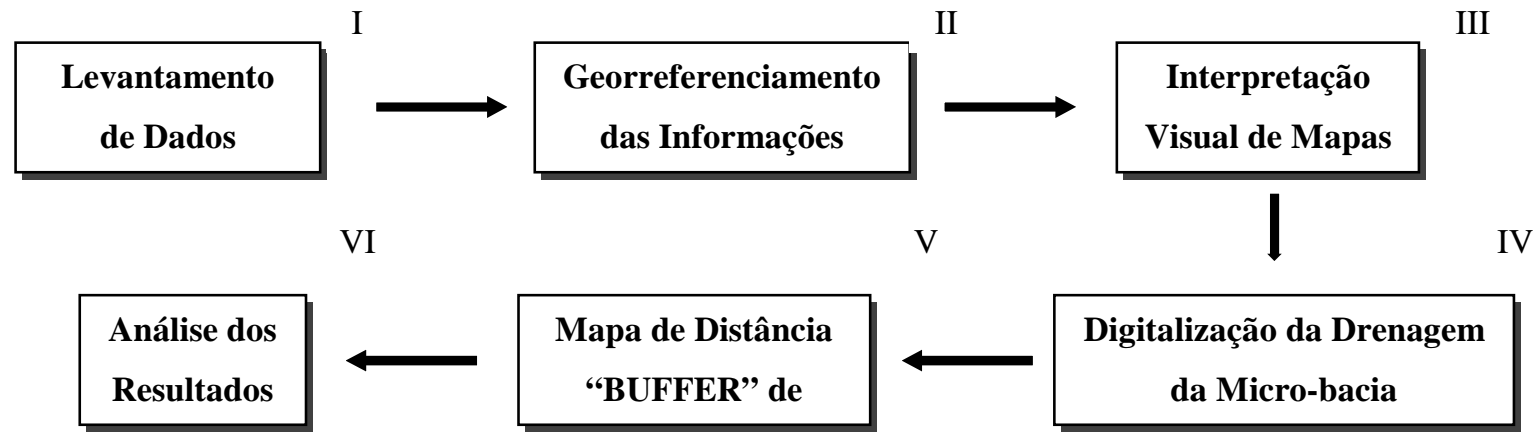

\subsection{Etapas Metodológicas:}

A seguir são explicitadas as etapas metodológicas que propiciaram a realização do referente trabalho.

I - Levantamento de Dados: Fase que compreendeu na seleção da área de estudo, na aquisição das imagens de satélite, das cartas topográficas e do limite municipal e urbano posteriormente usado no SIG.

a. As imagens utilizadas foram do sensor Thematic Mapper (TM) do satélite Landsat 5, bandas 3, 4 e 5, com resolução 30 x 30 metros nas datas de 17/07/1987, 28/07/1997 e 25/08/2007 correspondentes a órbita/ponto 218/76.

b. Foram utilizadas duas cartas topográficas do município de Cunha com a intenção de obter a totalidade da área urbana, as quais se encontram na escala de 1:10.000 na projeção UTM/Córrego Alegre. 
c. Os dados digitais correspondente ao perímetro urbano e ao limite municipal foram encontrados no site do Instituto Brasileiro de Geografia e Estatística (IBGE) sob o domínio: <www.ibge.gov.br>, no formato Shapefile (.shp), com projeção POLYCONIC/SAD69.

II - O georreferenciamento das imagens de satélite foi realizado utilizando o Sistema de Processamento de Informações Georreferenciado - SPRING versão 4.3.3. Utilizou-se como referência a imagem do satélite ASTER de 14 metros de resolução espacial, a qual pode ser obtida através do projeto GEOCOVER/NASA disponibilizado no formato Mr. Sid (.sid) em projeção UTM/WGS-84. Após a obtenção da imagem foi realizado o registro entre as imagens, através da aquisição de pontos de controle e utilizando um polinômio de $1^{\circ}$ ordem para a correção das distorções geométricas presentes nas imagens Landsat. Esta fase contou com a digitalização das cartas topográficas e o registro no software SPRING.

III - A etapa contou com a aplicação de contraste nas imagens do satélite aumentando o espalhamento dos níveis de cinza com o objetivo de melhorar a qualidade, permitindo desta maneira a identificação da mancha urbana nos três períodos de coleta. Após a aplicação do contraste foi gerada uma imagem sintética aplicando as cores R (vermelho), G (Verde) e B (Azul) as respectivas bandas 4, 5 e 3 do satélite, possibilitando a identificação da disposição da mata ciliar nos rios que compõem a micro-bacia em questão. Posteriormente com a classificação das manchas urbanas houve a sobreposição das mesmas, obtendo o crescimento urbano dos últimos vinte anos.

IV - A drenagem foi digitalizada utilizando a ferramenta de edição vetorial do SPRING, tendo como base as cartas topográficas de 1:10.000, possibilitando a identificação da microbacia do Córrego do Rodeio situada dentro do perímetro urbano.

V - Após a identificação da drenagem na etapa anterior foi possível elaborar, com base no Código Florestal, um mapa de distância (buffer) correspondente as áreas de preservação permanente dos rios. Para isso foi usada a ferramenta "mapa de distância" contida no software e que consiste em um tipo de análise de proximidade que apresenta zonas com larguras especificadas (distância) em torno de um geo-objeto de referência (ponto, linha ou polígono). (DPI, 2008, p.108).

VI - A análise dos resultados foi feita cruzando a mancha urbana dos três anos de coleta com as áreas de preservação permanente geradas na etapa $\mathrm{V}$, o que permitiu a identificação e quantificação das áreas de invasão da mancha urbana nas APP's da micro-bacia do Córrego do Rodeio. As manchas urbanas identificadas apresentaram em seu interior áreas de pouca refletância na imagem, consideradas áreas não urbanizadas como mostra a figura abaixo. 


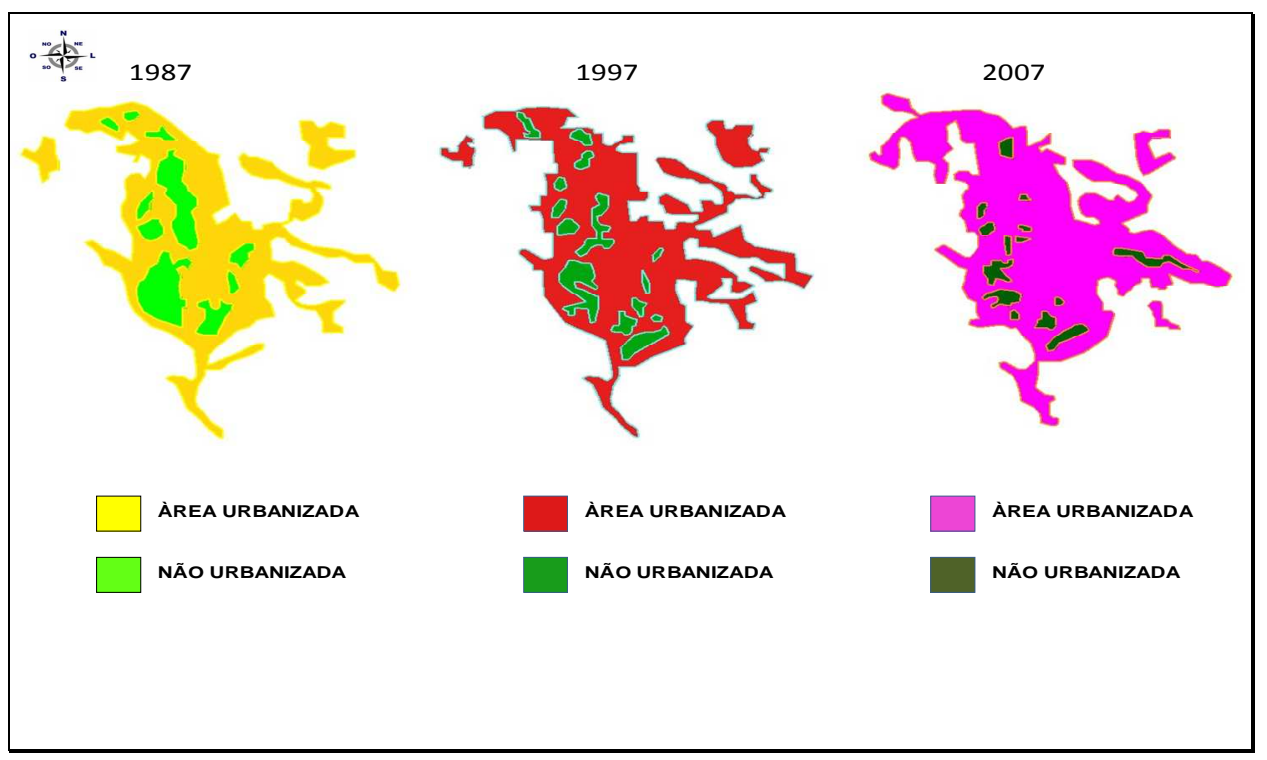

Figura 2 - Mancha Urbana.

Pôde-se observar uma diminuição de 1987 para 2007, mais visível em algumas áreas a nordeste, sudeste e noroeste (Figura 3), possivelmente áreas de solo exposto em 1987 e que vem se regenerando por não ter sido consolidada como área urbana até 2007. Em contrapartida observa-se um adensamento no interior da mancha urbana, diminuindo as áreas identificadas como sendo não urbanizadas, em sua maioria áreas de nascentes.

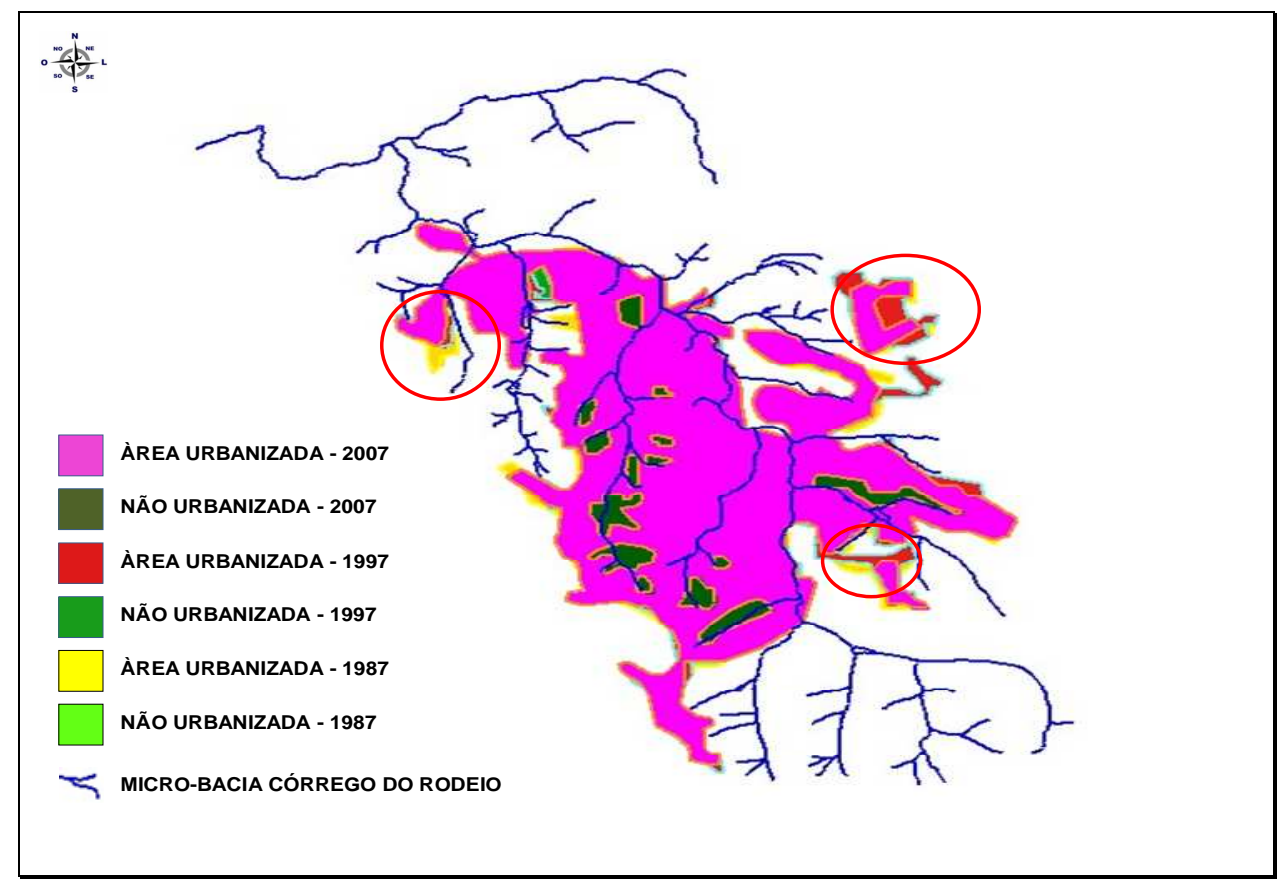

Figura 3 - Cruzamento das Manchas Urbanas e disposição da Micro-bacia.

Com a identificação das APP's da micro-bacia, foi capaz apontar a área total de preservação permanente como sendo de aproximadamente $2,533 \mathrm{~km}^{2}$, após o cruzamento com a mancha urbana gerou-se um mapa de invasão (Figura 4), obtendo desta forma a quantificação da invasão da área urbana em área de preservação permanente correspondente a margem de rio, descrita na Tabela 1. 


\begin{tabular}{|c|c|c|c|}
\hline & 1987 & 1997 & 2007 \\
\hline ÁREA & $0,395 \mathrm{~km}^{2}$ & $0,507 \mathrm{~km}^{2}$ & $0,684 \mathrm{~km}^{2}$ \\
\hline$\%$ & 15,6 & 20 & 27 \\
\hline
\end{tabular}

Tabela 1 - Área total e porcentagem de APP`s ocupadas.

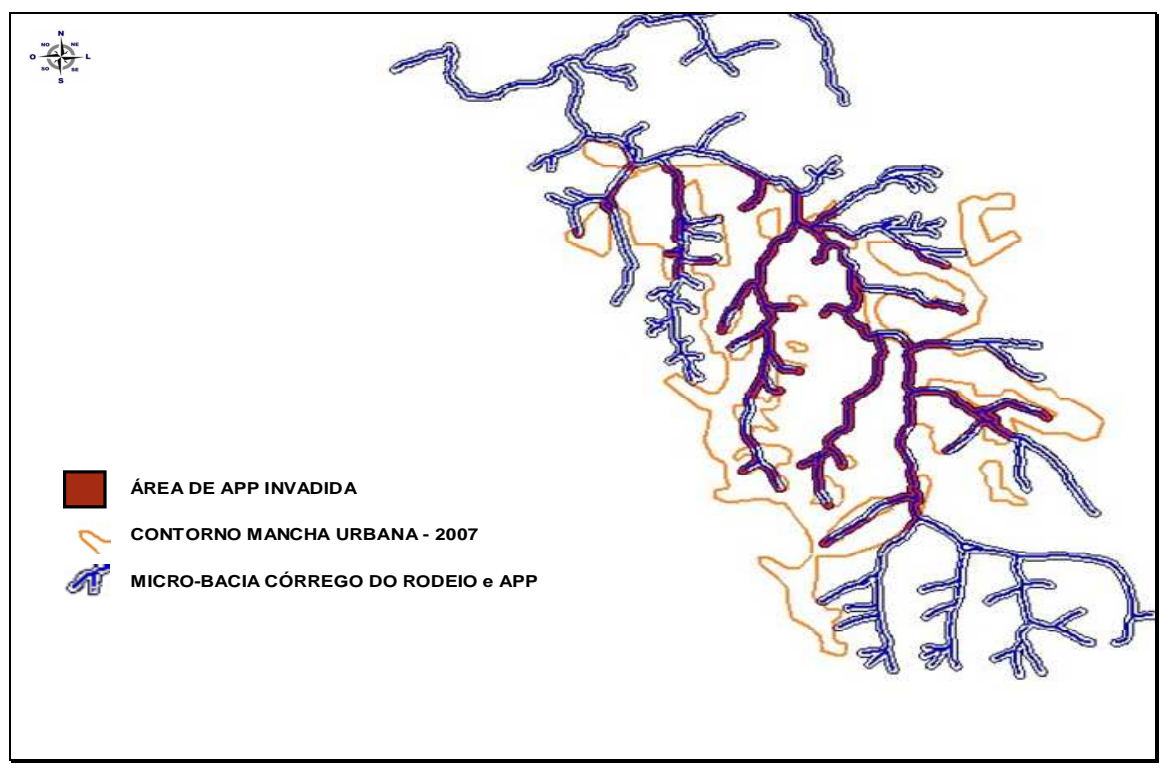

Figura 4 - Cruzamento do limite da mancha urbana com APP`s.

\section{Conclusão}

O município de Cunha por ser considerado Estância Climática (1948), devido ao clima e paisagem peculiar, precisa levar em consideração ações de preservação e conservação do ambiente, bem como a preocupação em manter uma relação harmoniosa entre sociedade e natureza. Com o aumento da população urbana de 36\% em 1980 para 53,7\% em 2000 (IBGE), o crescimento urbano tornou-se inevitável o que acabou gerando diversos problemas estruturais como alguns loteamentos irregulares, contribuindo para o crescimento desordenado da cidade. Devido à baixa resolução das imagens do satélite LANDSAT não podemos inferir com precisão os resultados levantados, mas a importância do trabalho está na utilização do sensoriamento remoto como uma ferramenta de auxilio para o poder público municipal, identificando as áreas de preservação permanentes ocupadas ou não ocupadas da micro-bacia que corta a área urbanizada do município, servindo de subsídio para políticas públicas como, por exemplo, leis de zoneamento.

\section{Bibliografia}

BRASIL. Decreto-lei no ${ }^{\mathbf{0}} \mathbf{1 0 . 2 5 7}$, de 10 de julho de 2001. Regulamenta os arts. 182 e 183 da Constituição Federal. Disponível em: <http://www.planalto.gov.br/CCIVIL/Leis/LEIS_2001/L10257.htm>, acesso em 29 de março de 2009.

BRASIL. Lei $\mathbf{n}^{\mathbf{0}} \mathbf{7 . 0 8 3}$, de 18 de julho de 1989. Regulamenta o art. $2^{\circ}$ do Código Florestal. Disponível em: 〈http://www.planalto.gov.br/CCIVIL/LEIS/L4771.htm>, acesso em 29 de março de 2009. 
DIVISÃO DE PROCESSAMENTO DE IMAGEM (DPI). Introdução ao SPRING. INPE, São José dos Campos, 2009.

INSTITUTO BRASILEIRO DE GEOGRAFIA E ESTATÍSTICA (IBGE). Banco de Dados Agregados: Demográfico e Contagem. SIDRA (Sistema IBGE de Recuperação Automática). Disponível em: <http://www.sidra.ibge.gov.br/>, acesso em 19 de março de 2009.

MARCELINO E. V. Desastres naturais e geotecnologias: conceitos básicos. INPE, Santa Maria, $2007 . \quad$ Disponível em: <http://www.inpe.br/crs/geodesastres/imagens/publicacoes/conceitosbasicos.pdf $>$. acesso em 15 de abril de 2009.

MÜLlER, Nice L. O Fato Urbano na Bacia do Rio Paraíba: Estado de São Paulo. Rio de Janeiro: Fundação IBGE, 1969.

PREFEITURA MUNICIPAL DA ESTÂNCIA CLIMÁTICA DE CUNHA. Dados Municipais. Cunha/SP, 2009.

SANTOS, Milton. A urbanização brasileira. 5. ed. São Paulo: Editora da Universidade de São Paulo, 2005. 